\title{
PUMP-INDUCED PLATELET AGGREGATION IN ALBUMIN-COATED EXTRACORPOREAL SYSTEMS
}

Piet Borgdorff, PhD

Rogier H. van den Berg, MsC

Martijn A. Vis, PhD

Gerard C. van den Bos, MD, PhD

Geert Jan Tangelder, MD, PhD
Objective: Coating of extracorporeal systems with heparin does not prevent platelet activation and subsequent bleeding disorders. We investigated whether this could be due to elevated shear stress caused by a roller pump. Methods: Human or rat blood was made to flow through an uncoated or an albumin-coated medical polyvinyl chloride tube with or without a roller pump. Aggregation of platelets in the tubing was recorded continuously with a photometric device. Results: Although in vitro gravitational flow in uncoated tubes caused immediate platelet aggregation and platelet loss, this remained absent in coated tubes. When the pump was started in experiments with a coated tube strong platelet aggregation was observed and platelet count fell within 5 minutes to $78 \% \pm 2 \%$ and $71 \% \pm 3 \%$ of control values in human and rat blood, respectively. In vivo, no aggregation was observed during spontaneous flow in rats with an albumin-coated tube running from the carotid artery to the femoral artery, but aggregation started as soon as the blood was pumped. Pump-induced platelet aggregation, both in vitro and in vivo, could be prevented with aurintricarboxylic acid, which specifically inhibits shear-induced platelet aggregation as has recently been shown. Pump perfusion of blood in an uncoated tube did not elicit platelet aggregation. Conclusions: Pump perfusion of blood in coated systems elicits shear-induced platelet aggregation, which may be prevented by administration of substances that block the binding of von Willebrand factor to glycoprotein Ib receptors on the platelets. The effects of pumping on platelets are masked in uncoated circuits because of the dominant influence of blood-material contact. ( $J$ Thorac Cardiovasc Surg 1999;118:946-52)
U se of extracorporeal systems in cardiopulmonary bypass and dialysis often causes such adverse systemic effects as complement activation and bleeding disorders. These effects are generally believed to result largely from blood-material contact. Bleeding disorders have been attributed to thrombocytopenia and platelet dysfunction caused by platelet adhesion ${ }^{1,2}$ and contact activation. ${ }^{3-5}$ Coating the system with heparin reduces complement activation, ${ }^{6-8}$ platelet adhesion, ${ }^{9-11}$ and

From the Laboratory for Physiology, Institute for Cardiovascular Research Vrije Universiteit (ICaR-VU), Amsterdam, The Netherlands.

Received for publication Dec 29, 1998; revisions requested May 4, 1999; revisions received July 8, 1999; accepted for publication Aug 17, 1999.

Address for reprints: Piet Borgdorff, PhD, Laboratory for Physiology, Vrije Universiteit, Van der Boechorststraat 7, 1081 BT Amsterdam, The Netherlands (E-mail: p.borgdorff.physiol@med.vu.nl).

Copyright (C) 1999 by Mosby, Inc.

$0022-5223 / 99 \$ 8.00+0 \quad \mathbf{1 2 / 1 / 1 0 2 2 8 9}$ contact activation, ${ }^{12}$ but bleeding and platelet activation are still present. ${ }^{13-17}$ Therefore other causes of platelet activation might still exist.

One of these causes could be the use of roller or centrifugal pumps, indispensable in many extracorporeal circuits. Pumps may indirectly activate platelets by causing lysis of red blood cells, with subsequent release of adenosine diphosphate (ADP). Pumps have therefore continuously been improved to reduce hemolysis. Nevertheless, the problem of platelet activation in extracorporeal systems has not been resolved.

Little attention has been paid to the possibility that intermittent increases in shear stress caused by the pumping can activate platelets more directly. Effects of shear stress on platelet behavior have mainly been studied in vitro with viscometers ${ }^{18-21}$ but are demonstrable in vivo as well. In a previous study on rats with an albumin-coated extracorporeal tube running from the carotid artery to the distal femoral artery we continuously measured aggregate formation and found that 


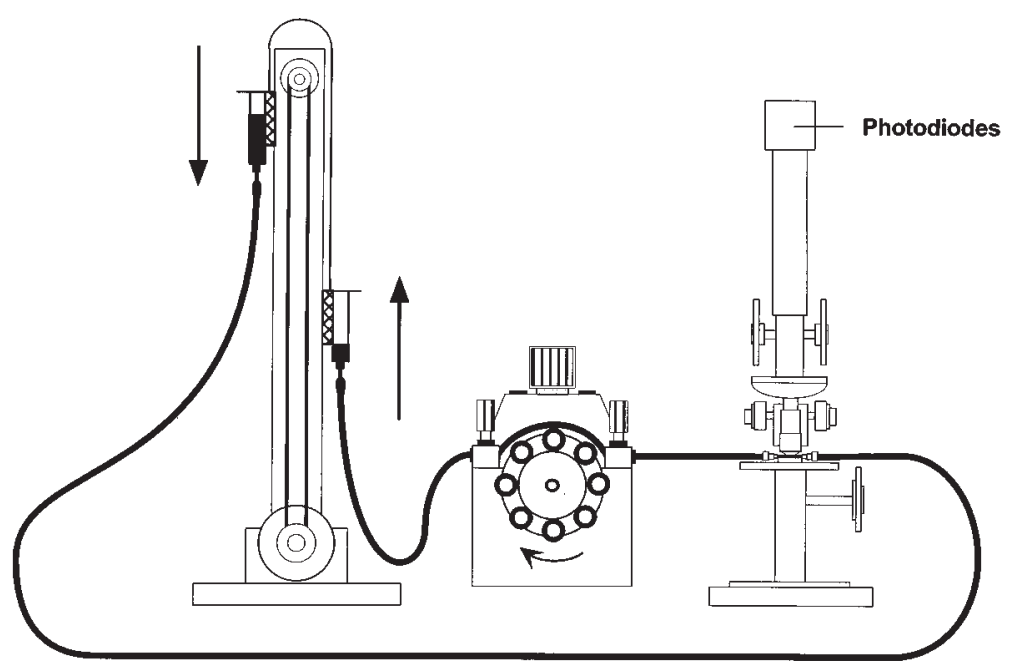

Fig 1. Setup for in vitro experiments. Blood flow was generated either by gravity or by roller pump. Gravitational flow was maintained by servo-controlled up-and-down motion of open syringes at each tube end (arrows). For pump perfusion one tube end was disconnected from syringe and put in other syringe and pump was started after tightening its rollers. Platelet aggregation was continuously monitored in an albumin-coated glass capillary inserted in circuit and placed on microscope stage. Changes in light transmission from passage of aggregates were detected by photodiodes.

platelets easily aggregate in areas of increased shear stress caused by partial occlusion of the tube..$^{22}$

In this study we therefore tested the hypothesis that in a coated extracorporeal system the roller pump also evokes platelet aggregation. Albumin was employed as the coating to avoid possible direct effects of surfacebound heparin on platelets. Albumin coating has been reported to be as effective as heparin coating in preventing platelet aggregation and activation as a result of blood-material contact. ${ }^{2,9,10,23}$ To elucidate the role of shear stress we studied whether pump-induced platelet aggregation could be prevented with aurintricarboxylic acid (ATA), a synthetic triphenylmethane dye that specifically prevents shear-induced platelet aggregation without affecting aggregation induced by ADP, collagen, epinephrine, thrombin, or arachidonic acid. ${ }^{24,25}$ Experiments were done with human blood in vitro and with rat blood in vitro and in vivo.

\section{Methods}

\section{Blood collection for in vitro experiments}

Human blood. With an 18-gauge needle $10 \mathrm{~mL}$ blood was collected from the antecubital veins of medication-free healthy volunteers. After the first drops were discarded the blood was allowed to flow in an albumin-coated tube that contained $1 \mathrm{~mL}$ heparin solution $(50 \mathrm{IU} / \mathrm{mL}$ ). Values (mean \pm SEM) for $\mathrm{pH}, \mathrm{PCO}_{2}$, and $\mathrm{Po}_{2}$ were $7.35 \pm 0.01,50.2 \pm 1.5 \mathrm{~mm}$ $\mathrm{Hg}$, and $30.1 \pm 2.5 \mathrm{~mm} \mathrm{Hg}$, respectively.

Rat blood. Male Wistar rats (325-400 g) were anesthetized with an intramuscular bolus of ketamine $(10 \%, 60 \mathrm{mg} / \mathrm{kg}$, Kombivet) and subsequent intraperitoneal administration of pentobarbital (Nembutal, $25 \mathrm{mg} / \mathrm{kg}$ ). After cannulation of a common carotid artery, the animals received heparin (800 $\mathrm{IU} / \mathrm{kg}$ ) and 10 to $12 \mathrm{~mL}$ blood was slowly collected in a syringe. Values (mean $\pm \mathrm{SEM}$ ) for $\mathrm{pH}, \mathrm{PCO}_{2}$, and $\mathrm{PO}_{2}$ were $7.37 \pm 0.01,42.5 \pm 1.5 \mathrm{~mm} \mathrm{Hg}$, and $74.4 \pm 3.4 \mathrm{~mm} \mathrm{Hg}$, respectively.

Setup for in vitro experiments. To study the influence of the pump on platelet behavior we used a device in which blood flow was generated either by gravity or by a pump (Fig 1). This setup consisted of 2 syringes positioned at different heights and connected by medical-grade polyvinyl chloride tubing (1.5 mm inner diameter, $100 \mathrm{~cm}$ long). Halfway along this tube a piece of pump tube $(1.65 \mathrm{~mm}$ inner diameter, $7 \mathrm{~cm}$ long; Gilson, Inc, Middleton, Wis) was inserted and loosely placed in a small noncommercial roller pump with rotator and roller diameters of 35 and $6 \mathrm{~mm}$, respectively. At $10 \mathrm{~cm}$ from the pump the polyvinyl tube was serially connected to a glass capillary tube $(0.6 \mathrm{~mm}$ inner diameter $)$ on the stage of a microscope for continuous measurement of platelet aggregation, as has been described previously. ${ }^{22}$ The system was filled with 7 to $8 \mathrm{~mL}$ blood. The difference in height between the 2 syringes $(30 \mathrm{~cm})$ caused a flow of approximately 6 $\mathrm{mL} / \mathrm{min}$ that lasted about 1 minute; at that point the nearly empty upper syringe was automatically lowered with an electromotor and the full syringe was elevated to continue flow. In this way there was no need to decant the blood and contact of blood with air was minimized. To replace gravitational flow by pump flow a calibrated screw on the pump was tightened to set the pump so that it was just occlusive for blood. 
Then a tube end was detached and placed into the other reservoir and the pump was started. The whole system was either coated with albumin or not coated and was placed in a polymethyl methacrylate (Perspex; ICI Acrylics, Inc, Nederland, Tex) box with the temperature regulated at $32^{\circ} \mathrm{C} \pm 1{ }^{\circ} \mathrm{C}$. The method of coating has been described previously. ${ }^{26}$ Tests with radioactively labeled albumin showed that the coating consisted of 1 to 2 monolayers and was stable during at least 4 hours of blood perfusion.

In vivo experiments. Anesthesia was induced in rats as described previously and maintained by continuous intraperitoneal infusion of 10 to $14 \mathrm{mg} \cdot \mathrm{kg}^{-1} \cdot \mathrm{h}^{-1}$ pentobarbital with a Harvard infusion pump (model 11; Harvard Apparatus, Inc, Holliston, Mass). After tracheotomy the animals' lungs were ventilated with a mixture of room air and oxygen (3:1) at a rate of 90 breaths/min. Tidal volume was adjusted so that $\mathrm{PaCO}_{2}$ was approximately $40 \mathrm{~mm} \mathrm{Hg}$. Arterial $\mathrm{pH}$ ranged from 7.33 to 7.42 and $\mathrm{PaO}_{2}$ ranged from 76 to $110 \mathrm{~mm} \mathrm{Hg}$. Body temperature was measured with a rectal probe and kept at $37.5^{\circ} \mathrm{C}$ by a means of servo-controlled heating pad.

After cannulation of the central part of a common carotid artery (20 gauge) and the distal part of the left femoral artery (22 gauge) the cannulas were connected with medical-grade polyvinyl chloride tubing $(1.5 \mathrm{~mm}$ inner diameter, $30 \mathrm{~cm}$ long) filled with heparinized saline solution. During the connection procedure flow to the leg was interrupted for 2 to 3 minutes only. Part of the tube was loosely positioned in the roller pump. If the tube in the pump was not compressed, blood flowed spontaneously $(2-4 \mathrm{~mL} / \mathrm{min})$ as a result of the difference between central carotid arterial and distal femoral arterial pressures. For transition to pump flow the tube was gradually compressed until flow stopped, and the pump was then started. Platelet aggregation in the tube between the pump and the femoral artery was continuously measured with the same photometric device used in the in vitro experiments. The whole system was coated with albumin. Aortic pressure was measured through a stainless steel T-piece inserted in the tube about $3 \mathrm{~cm}$ from the carotid cannula. Flow in the tubing was measured with a perivascular flow probe. A warming lamp above the extracorporeal circuit prevented the blood from cooling more than about $1{ }^{\circ} \mathrm{C}$.

All animal handling was in compliance with the "Guide for the Care and Use of Laboratory Animals" prepared by the Institute of Laboratory Animal Resources, National Research Council, and published by the National Academy Press, revised 1996.

Measurement of platelet behavior. The device for continuous detection of platelet aggregates has been described previously. ${ }^{22}$ Passage of aggregates through the glass capillary tube was indicated by short-duration voltage peaks from photocells. For quantification the signals were converted to uniform spikes with a spike processor and subsequently counted during fixed periods. In the in vivo experiments aggregate formation was related to the value found after injection of 2 ng ADP into the tube a few centimeters from the carotid cannula. The $2 \mathrm{ng}$ ADP was dissolved in $20 \mu \mathrm{L}$ saline solution and injected within half a second. This dose elicited strong platelet aggregation that just barely did not impede flow. Periodic inspection of blood samples under a microscope confirmed the results obtained with the continuous aggregometer; it also showed that aggregates seldom contained any leukocytes and that aggregates of fewer than 4 platelets were not detected.

For platelet counting and visual inspection of aggregates $0.1 \mathrm{~mL}$ blood was withdrawn from a syringe in the in vitro experiments and from the T-piece in the extracorporeal shunt in vivo. The blood was added to $150 \mu \mathrm{L}$ of a solution of ethylenediaminetetraacetic acid $(3.6 \mathrm{mg} / \mathrm{mL}$ saline solution), resulting in a final concentration of $6.6 \mathrm{mmol} / \mathrm{L}$, to stabilize the number of platelets and aggregates. From the ethylenediaminetetraacetic acid-diluted sample, $20 \mu \mathrm{L}$ was added to 2 $\mathrm{mL}$ Thromboplus (Sarstedt, Nürembrecht, Germany). Aggregates and platelets were counted in a Bürker counting chamber under phase contrast microscopy $(\times 400)$. Platelets were also counted with a Coulter Counter (model ZF; Coulter Corporation, Hialeah, Fla). Hemolysis was quantified by colorimetric determination of free hemoglobin in plasma at 600 nm (procedure No. 527; Sigma Chemical Co, St Louis, Mo).

Aurintricarboxylic acid. A trisodium salt of ATA (Aldrich Chemical Company, Bornem, Belgium) was dissolved (30 $\mathrm{mg} / \mathrm{mL}$ ) in phosphate buffer ( $\mathrm{pH} 7.4)$. In the in vivo experiments $35 \mathrm{mg} / \mathrm{kg}$ was infused intravenously within 10 minutes in rats that had not been earlier exposed to pump perfusion. In a previous study ${ }^{22}$ this dose had been found to effectively inhibit platelet aggregation in rats in which a mean shear stress of 231 dyne $/ \mathrm{cm}^{2}$ was generated by partial occlusion of a tube between the carotid artery and the femoral artery. In the in vitro experiments final concentrations of $1 \mathrm{mg} / \mathrm{mL}$ in rat blood and $100 \mu \mathrm{g} / \mathrm{mL}$ in human blood ${ }^{24,25}$ were used.

Statistics. All values are expressed as mean \pm SEM. Data were analyzed by 2 -way analysis of variance. If a significant $P$ value was present posttests for comparison between conditions (pump or no pump) at different times were performed with the Bonferroni multiple comparison procedure.

\section{Results}

Platelet aggregation in vitro and in vivo. Gravitational flow of rat blood through an uncoated tube $(\mathrm{n}=$ 7) immediately resulted in strong platelet aggregation (Fig 2, A). After 1.5 to 2 minutes aggregation decreased and remained more or less stable. Starting the pump 10 minutes later did not elicit additional aggregation. On the other hand, aggregation was absent or negligible during gravitational flow in albumin-coated tubes (Fig $2, B)$; this could even be maintained for longer than 1 hour and demonstrates the effectiveness of albumin coating to prevent platelet activation. The effect of starting the pump in a coated system in vitro, also illustrated in Fig 2, B, was immediate and strong aggregation. In addition, in vivo in rats with a coated tube between the carotid artery and the femoral artery no aggregation was observed with autoperfusion but aggregation start- 
A

Aggregation
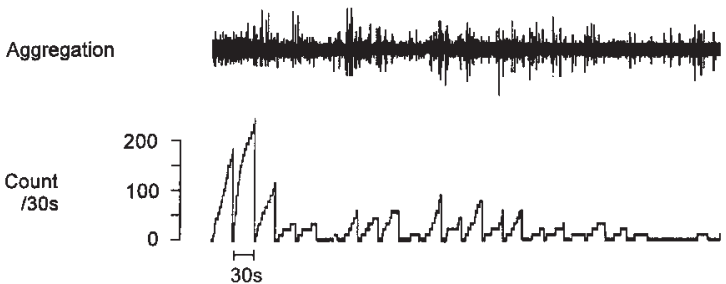
Flow
$\mathrm{ml} / \mathrm{min}$ $\left.\begin{array}{r}18 \\ 6 \\ -6\end{array}\right]$

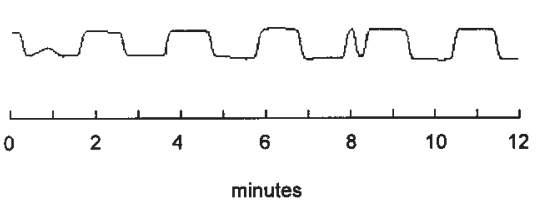

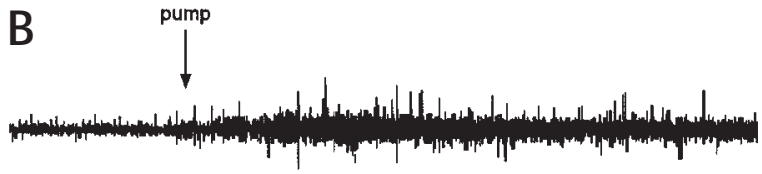
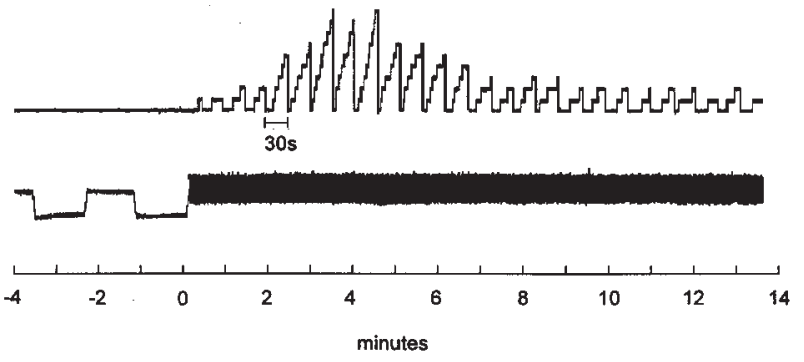

Fig 2. A, In vitro platelet aggregation during gravitational flow of rat blood in uncoated tube. Blood was added to system at time $0 . \mathbf{B}$, Absence of platelet aggregation in vitro in albumin-coated tube during gravitational flow and occurrence of aggregation at start of pump perfusion (arrow). Upper tracing shows signals from device measuring passage of platelet aggregates, middle tracing shows quantitation of these signals in 30 seconds, and lower tracing shows flow in system. Note that gravitational flow is bidirectional and pump flow is unidirectional.

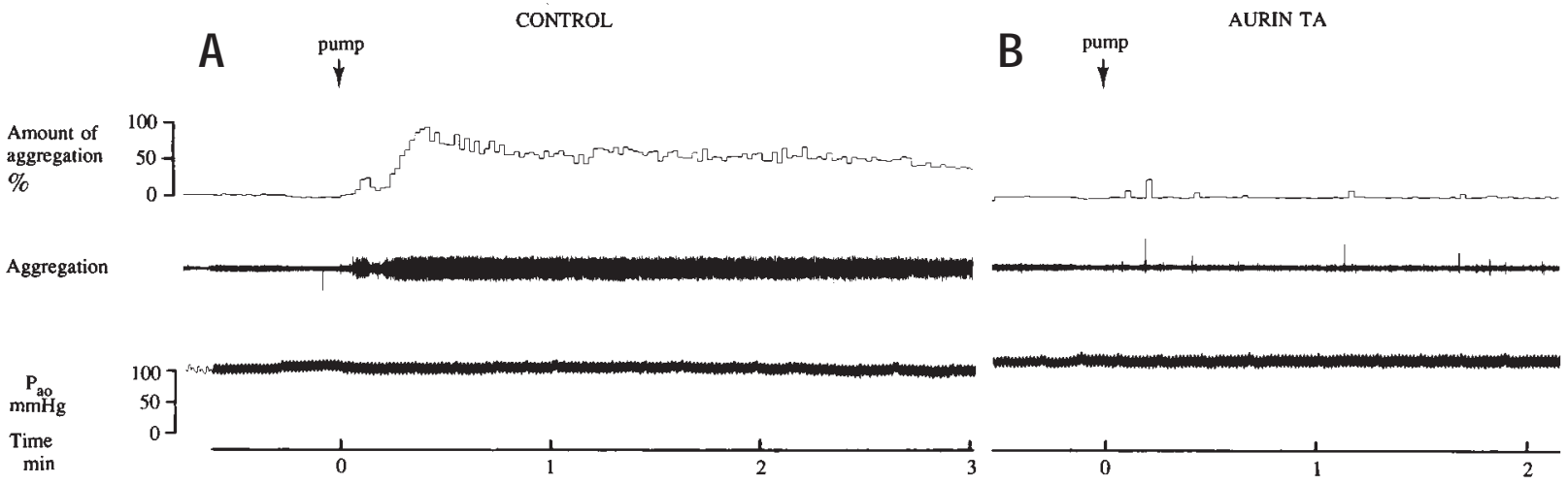

Fig 3. A, In vivo platelet aggregation in albumin-coated tube at start of pump perfusion (arrow). Pump flow was set equal to spontaneous flow. B, Inhibition of pump-induced platelet aggregation by ATA. Middle tracings show recorded signals, upper tracings show number of aggregates as percentage of value found after injection of $2 \mathrm{ng}$ ADP into tubing, and lower tracings show aortic pressure.

ed when the pump was turned on (Fig 3, A). In all experiments aggregation diminished after some minutes and thereafter stabilized at a lower level, which was maintained for the period of observation (60 minutes in vitro and 120 minutes in vivo). The pump start caused aortic pressure to decline from $125 \pm 5 \mathrm{~mm} \mathrm{Hg}$ to $115 \pm 6 \mathrm{~mm}$ $\mathrm{Hg}$ within 15 minutes, after which it remained stable. Reversal of pump perfusion to autoperfusion in vivo stopped the aggregation, indicating that the aggregates did not recirculate but probably either got stuck in the capillary bed of leg or lungs or disaggregated.
The amount of pump-induced platelet aggregation in coated tubes is quantitated in Fig 4. Aggregation in rat blood in vitro $(B)$ and in vivo $(C)$ was more pronounced and longer lasting than that in human blood in vitro $(A)$.

Role of shear stress in pump-induced platelet aggregation. In both the in vivo and the in vitro experiments ATA effectively prevented aggregation by pump perfusion (Fig 3, B, and Fig 4). In the in vivo experiments platelets started to aggregate more and more as the effect of ATA was wearing off after 1 to 1.5 hours. At the dose used ATA did not change aortic pressure or heart rate. 

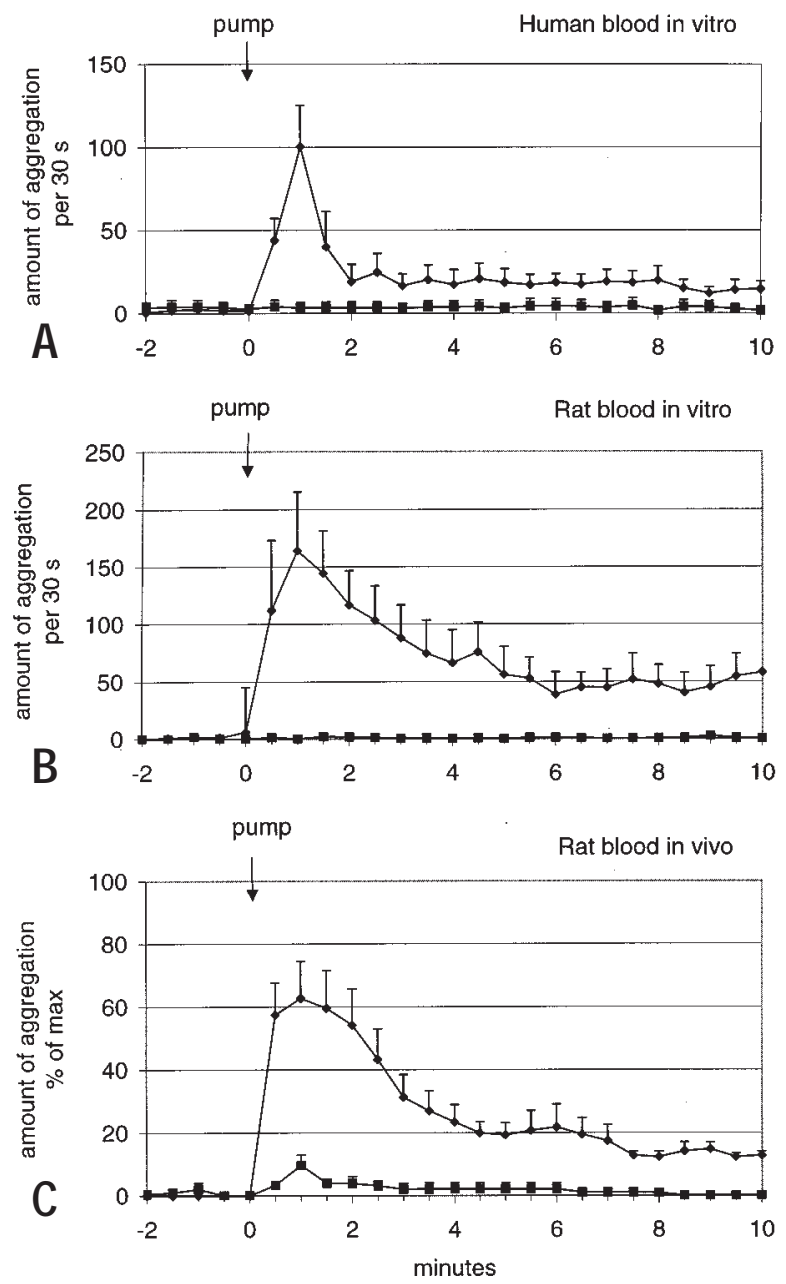

Fig 4. Occurrence of platelet aggregation during pump perfusion (arrows) in albumin-coated tube (filled diamonds) and its prevention with ATA (filled squares). Data points represent means; error bars represent SEM. A, Human blood in vitro (without ATA, $n=6$; with ATA, $n=3$ ). $\mathbf{B}$, Rat blood in vitro (without ATA, $n=9$; with ATA, $n=3$ ). C, Rat blood in vivo (without ATA, $n=5$; with ATA, $n=3$ ).

Platelet counts in vitro. During gravitational flow in coated tubes platelet count showed a small and gradual decrease during a period of 60 minutes (Fig 5) and no aggregation was observed. By contrast, when the pump was started after 10 minutes of gravitational flow (Fig 5), platelet count significantly $(P=.0001)$ decreased within 5 minutes in both human and rat blood. A further gradual decrease, similar to that noticed with gravitational flow, was seen thereafter. With ATA $(n=3)$ platelet counts after 60 minutes of pumping had diminished less than without ATA $(78 \% \pm 3 \%$ in human blood and $72 \% \pm 4 \%$ in rat blood).

In uncoated tubes $(\mathrm{n}=7)$ rat platelet number fell to
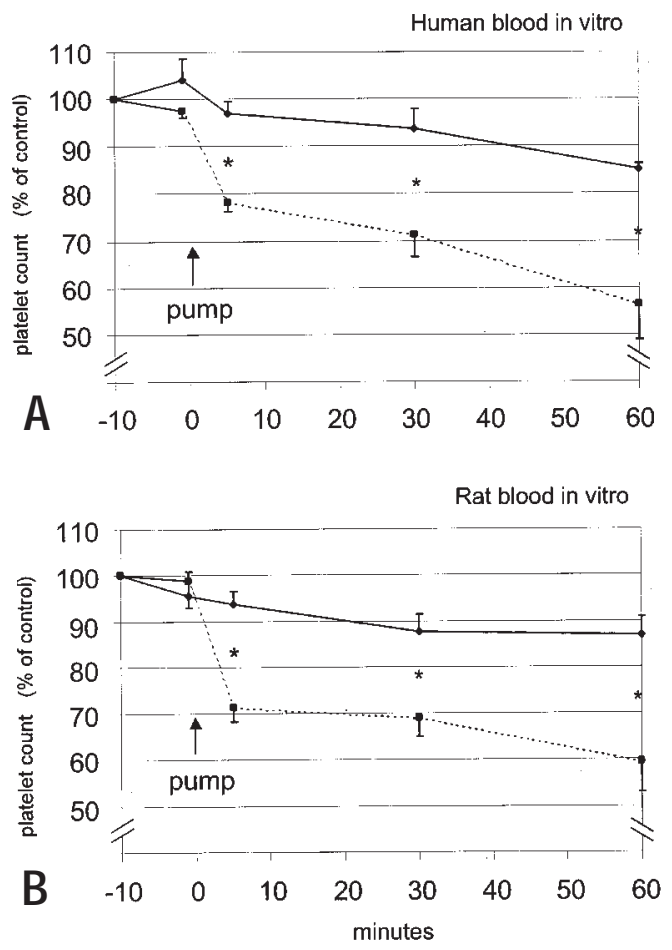

Fig 5. Platelet loss with pump perfusion (filled squares) and without pump perfusion (filled diamonds) in albumin-coated tube in vitro. Data points represent means; error bars represent SEM. Asterisk indicates significant difference between concomitant time points of pump flow and gravitational flow. A, Human blood (with pump, $\mathrm{n}=8$; without pump, $\mathrm{n}=3$ ). B, Rat blood (with pump, $\mathrm{n}=8$; without pump, $\mathrm{n}=7$ ).

$78 \% \pm 5 \%$ of control values within the first 10 minutes of gravitational flow. When the pump was started the count stabilized at about $62 \%$ within 20 minutes.

As appeared from platelet counts in blood that was kept 1 hour in Eppendorff vials, human platelets (loss to $78 \% \pm 4 \%$ of control value, $n=11$ ) seemed to be more vulnerable than rat platelets (loss to $99 \% \pm 9 \%$ of control value, $n=22$ ). Initial platelet counts for rat blood were more than 5 times the counts in human blood $\left(1039 \pm 65 \times 10^{9}\right.$ cells $/ \mathrm{L}$ vs $187 \pm 17 \times 10^{9}$ cells/L).

Conditions for pump-induced platelet aggregation. The pump-induced aggregation in vitro could only be observed when blood was handled with great care during the preparation procedure. It was often absent after contact of the blood with air or uncoated material, use of too much heparin, blood loss during cannulation, or vacuum sucking during blood collection. All these conditions caused platelet aggregation and platelet loss, as judged by microscopic inspection of the blood immediately after collection. Moreover, 
experiments with human blood $(\mathrm{n}=5)$ anticoagulated with $3.8 \%$ citrate, which does not inhibit agonistinduced platelet aggregation, showed that pumpinduced platelet aggregation was absent after even partial calcium chelation.

The importance of the occlusion setting of the pump was tested in vitro with rat blood $(n=3)$ by intentionally increasing its compression onto the tube. This was done at 20 minutes after the start of pump perfusion, when the initial pump-induced aggregation had leveled off. Elevated compression caused a gradual and continuous increase of aggregation that was clearly distinct from the immediate and temporary aggregation induced with the pump set to be just barely occlusive as in the other experiments. This effect was probably caused by hemolysis because in the experiments with increased compression the mean increase in plasma free hemoglobin levels after 60 minutes of pumping was $121 \pm 32 \mathrm{mg} / \mathrm{dL}$, whereas this value was $26 \pm 13$ $\mathrm{mg} / \mathrm{dL}$ in the in vitro experiments in which the pump was set to be just barely occlusive $(n=9)$. In the in vivo experiments the increase in plasma free hemoglobin level after 2 hours of pump perfusion was less than 1.32 $\pm 2.5 \mathrm{mg} / \mathrm{dL}(\mathrm{n}=5)$.

\section{Discussion}

Our results show that with human blood in vitro and with rat blood both in vitro and in vivo the use of roller pumps in albumin-coated extracorporeal systems causes platelet aggregation, even when hemolysis is negligible, and that elevated shear stress may be involved. Pump-induced platelet aggregation appeared to be a sensitive reaction. It was demonstrable only in coated circuits and when the blood was handled with great care. It could not be evoked after premature platelet activation by contact with uncoated material, vacuum suction of the blood, or contact with air. It was also absent after partial calcium chelation with $3.8 \%$ citrate, suggesting that shear stress is a weaker stimulus for platelet aggregation than are the agonists used to test platelet reactivity in vitro. The clinical situation in which blood is heparinized and coated systems are increasingly used seems to present conditions under which pump-induced platelet aggregation is likely to occur. Although roller pumps in the clinical setting differ from the small pump used in our experiments, we think that pumps with characteristics different from ours will elicit platelet aggregation as well because aggregation was demonstrable already by gentle repetitive squeezing of the tube with the fingers.

Contact of blood with our uncoated tubes caused immediate strong platelet aggregation and platelet loss, confirming that this occurrence is a "first pass" effect. ${ }^{17}$
It may even be stronger in the uncoated capillary tubes of clinically used filters, oxygenators, and artificial kidneys. The last, for example, have a surface to blood volume ratio of $163 \mathrm{~cm}^{2} / \mathrm{mL}$, whereas in our system corresponding values were $26 \mathrm{~cm}^{2} / \mathrm{mL}$ for the in vitro experiments and $12 \mathrm{~cm}^{2} / \mathrm{mL}$ for the in vivo experiments.

Our finding that the pump-induced aggregation could be prevented with ATA suggests that elevated shear stress plays a prominent role because ATA specifically inhibits shear-induced platelet aggregation by binding to the von Willebrand factor but does not suppress the reactions of platelets to other agonists. ${ }^{24,25}$ The ATA dose used in this study has been shown to inhibit platelet aggregation caused by a shear stress of $231 \mathrm{dyne} / \mathrm{cm}^{2}$, which resulted from partial tube occlusion. In addition to shear stress pumping may have caused the release of platelet-activating substances from red blood cells as a result of hemolysis. Although this is a real possibility in clinical cardiopulmonary bypass, in which the increase in plasma free hemoglobin levels usually varies from 26 to $82 \mathrm{mg} / \mathrm{dL},{ }^{27,28}$ it seems a less likely cause of platelet aggregation in our experiments. The increase in plasma free hemoglobin in our in vivo experiments was less than $1.32 \mathrm{mg} / \mathrm{dL}$, indicating that hemolysis was limited. Even in our in vitro setup, in which erythrocytes probably were more vulnerable, free plasma hemoglobin concentration only increased to values in the lower range of those seen in clinical practice. Moreover, the time course of platelet aggregation caused by hemolysis could be distinguished from that related to elevated shear stress in our experiments. When we intentionally augmented hemolysis by tightening the rollers of the pump platelet aggregation increased slowly and steadily, whereas aggregation caused by pumping at the proper setting was a short lasting phenomenon.

Pump-induced aggregation could be prevented with ATA, which also attenuated the loss of platelets. Whether ATA in its commercially available form can be employed in human beings is not known, although several authors suggest its potential usefulness ${ }^{21}$ and no toxic effects have been found in dogs. ${ }^{25}$ Nevertheless, it might be safer to develop substances that are more specifically suited for human use. Like ATA, these substances should reversibly inhibit the binding of von Willebrand factor to platelet glycoprotein Ib receptors. One could think of recombinant fragments of von Willebrand factor-like VCL (leucine ${ }^{504}-$ lysine $^{728}$ ), a peptide which binds to glycoprotein $\mathrm{Ib}$ receptors in human blood. ${ }^{29}$ In an experiment on a rat in vivo we used VCL (gift of Professor J. J. Sixma, University Hospital, Utrecht, The Netherlands). In the final concentration used (about $2 \mu \mathrm{mol} / \mathrm{L}$ ) VCL largely prevented platelet aggregation during pumping in vivo. 
Our results show that the use of a roller pump in extracorporeal circuits causes platelet aggregation. This seems to be the result of elevated shear stress in the blood within the pump tube because the platelet aggregation can be prevented with ATA. Our results also indicate that the effects of pumping on platelets are masked in uncoated circuits because of the dominant influence of blood-material contact.

\section{REFERENCES}

1. Courtney JM, Travers M, Bowry SK, Prentice CR, Lowe GD, Forbes CD. Measurement of platelet loss in the blood compatibility assessment of biomaterials. Biomaterials 1987;8:231-3.

2. Engbers GH, Dost L, Hennink WE, Aarts PA, Sixma JJ, Feijen J. An in vitro study of the adhesion of blood platelets onto vascular catheters. Part I. J Biomed Mater Res 1987;21:613-27.

3. Szycher M. Thrombosis, hemostasis, and thrombolysis at prosthetic interfaces. In: Szycher M, editor. Biocompatible polymers, metals, and composites. Lancaster [Pa]: Technomic Publishing; 1983. p. 1-33.

4. Matata BM, Courtney JM, Sundaram S, Wark S, Bowry SK, Vienken J, et al. Determination of contact phase activation by the measurement of the activity of supernatant and membrane surface-adsorbed factor XII (FXII): its relevance as a useful parameter for the in vitro assessment of haemodialysis membranes. J Biomed Mater Res 1996;31:63-70.

5. Matata BM, Wark S, Sundaram S, Courtney JM, Gaylor JD, Bowry SK, et al. In vitro contact phase activation with haemodialysis membranes: role of pharmaceutical agents. Biomaterials 1995;16:1305-12.

6. Gu YJ, van Oeveren W, Akkerman C, Boonstra PW, Huyzen RJ, Wildevuur CR. Heparin-coated circuits reduce the inflammatory response to cardiopulmonary bypass. Ann Thorac Surg 1993;55: 917-22.

7. te Velthuis H, Jansen PG, Hack CE, Eijsman L, Wildevuur CR. Specific complement inhibition with heparin-coated extracorporeal circuits. Ann Thorac Surg 1996;61:1153-7.

8. Jansen PG, te Velthuis H, Huybregts RA, Paulus R, Bulder ER, van der Spoel HI, et al. Reduced complement activation and improved postoperative performance after cardiopulmonary bypass with heparin-coated circuits. J Thorac Cardiovasc Surg 1995;110:829-34.

9. Olsson P, Lagergren H, Larsson R, Radegran K. Prevention of platelet adhesion and aggregation by a glutardialdehyde-stabilized heparin surface. Thromb Haemost 1977;37:274-82.

10. Takano H, Nakano S, Kadoba K, Kaneko M, Miyamoto Y, Ohtake S, et al. Evaluation of the biocompatibility of a new method for heparin coating of a cardiopulmonary bypass circuit. ASAIO J 1992;38:M390-4.

11. Gorman RC, Ziats N, Rao AK, Gikakis N, Sun L, Khan MM, et al. Surface-bound heparin fails to reduce thrombin formation during clinical cardiopulmonary bypass [see comments]. J Thorac Cardiovasc Surg 1996;111:1-11; discussion 11-2.

12. te Velthuis H, Baufreton C, Jansen PG, Thijs CM, Hack CE, Sturk A, et al. Heparin coating of extracorporeal circuits inhibits contact activation during cardiac operations. J Thorac Cardiovasc Surg 1997;114:117-22.

13. Boonstra PW, Gu YJ, Akkerman C, Haan J, Huyzen R, van Oeveren W. Heparin coating of an extracorporeal circuit partly improves hemostasis after cardiopulmonary bypass. J Thorac Cardiovasc Surg 1994;107:289-92.

14. van der Kamp KW, van Oeveren W. Contact, coagulation and platelet interaction with heparin treated equipment during heart surgery. Int J Artif Organs 1993;16:836-42.

15. Muehrcke DD, McCarthy PM, Kottke-Marchant K, Harasaki H, Pierre-Yared J, Borsh JA, et al. Biocompatibility of heparin-coated extracorporeal bypass circuits: a randomized, masked clinical trial. J Thorac Cardiovasc Surg 1996;112:472-83.

16. Palatianos GM, Dewanjee MK, Kapadvanjwala M, Novak S, Sfakianakis GN, Kaiser GA. Cardiopulmonary bypass with a surface-heparinized extracorporeal perfusion system. ASAIO Trans 1990;36:M476-9.

17. Plötz FB, van Oeveren W, Aloe LS, Riley MK, Hultquist KA, et al. Prophylactic administration of tranexamic acid preserves platelet numbers during extracorporeal circulation in rabbits. ASAIO Trans 1991;37:M416-7.

18. Jen CJ, McIntire LV. Characteristics of shear-induced aggregation in whole blood. J Lab Clin Med 1984;103:115-24.

19. Kawano K, Ikeda Y, Handa M, Kamata T, Anbo H, et al. Enhancing effect by heparin on shear-induced platelet aggregation. Semin Thromb Hemost 1990;16(suppl):60-5.

20. Moake JL, Turner NA, Stathopoulos NA, Nolasco L, Hellums JD. Shear-induced platelet aggregation can be mediated by vWF released from platelets, as well as by exogenous large or unusually large vWF multimers, requires adenosine diphosphate, and is resistant to aspirin. Blood 1988;71:1366-74.

21. Alevriadou BR, Moake JL, Turner NA, Ruggeri ZM, Folie BJ, Phillips MD, et al. Real-time analysis of shear-dependent thrombus formation and its blockade by inhibitors of von Willebrand factor binding to platelets. Blood 1993;81:1263-76.

22. Borgdorff P, Kok WE, Vis MA, van den Bos GC. Vasodilation by shear-induced platelet aggregation in extracorporeal circuits. Am J Physiol 1994;266:H891-7.

23. Mulvihill JN, Faradji A, Oberling F, Cazenave JP. Surface passivation by human albumin of plasmapheresis circuits reduces platelet accumulation and thrombus formation: experimental and clinical studies. J Biomed Mater Res 1990;24:155-63.

24. Phillips MD, Moake JL, Nolasco L, Turner N. Aurin tricarboxylic acid: a novel inhibitor of the association of von Willebrand factor and platelets. Blood 1988;72:1898-903.

25. Weinstein M, Vosburgh E, Phillips M, Turner N, Chute Rose L, Moake J. Isolation from commercial aurintricarboxylic acid of the most effective polymeric inhibitors of von Willebrand factor interaction with platelet glycoprotein Ib: comparison with other polyanionic and polyaromatic polymers. Blood 1991;78:2291-8.

26. Borgdorff P, Kok WE, van den Bos GC. Extracorporeal circuits and autoregulation: effect of albumin coating. Am J Physiol 1992; 263:H1397-401.

27. Murakami F, Usui A, Hiroura M, Kawamura M, Koyama T, Murase M. Clinical study of totally roller pumpless cardiopulmonary bypass system. Artif Organs 1997;21:803-7.

28. Komoda T, Maeta H, Imawaki S, Shiraishi Y, Arioka I, Fukunaga $\mathrm{S}$, et al. A pulsatile cardiopulmonary bypass system that prevents negative pressure at the membrane oxygenator. ASAIO J 1993;39:936-41.

29. Sixma JJ, Ijsseldijk MJ, Hindriks G, van Zanten GH, Gorecki M, Panet A, et al. Adhesion of blood platelets is inhibited by VCL, a recombinant fragment (leucine504 to lysine728) of von Willebrand factor. Arterioscler Thromb Vasc Biol 1996;16:64-71. 